


\section{As políticas públicas para a agricultura familiar no Brasil: um ensaio a partir da abordagem cognitiva}

\section{Public policies for formily forming in Brozil: an essay from a cognitive approach}

Catia Grisa

\section{Resumo}

Este artigo analisa a construção de três políticas públicas para a agricultura familiar, cada uma delas criada em um período histórico específico e com instrumentos diferenciados: Programa de Apoio ao Pequeno Produtor Rural (PAPP), Programa Nacional de Fortalecimento da Agricultura Familiar (PRONAF) e Programa de Aquisição de Alimentos (PAA). Ancorado na abordagem cognitiva de análise das políticas públicas, o artigo analisa as ideias que deram origem a esses programas, os atores que as construíram, a negociação de ideias entre os atores e a institucionalização das mesmas em políticas públicas.

Palavras-chaves: Política pública; Ideias; Agricultura familiar.

\begin{abstract}
This paper analyzes the construction of three public policies to the family farming, which are created at diverse historical circumstances and with different instruments: Programa de Apoio ao Pequeno Produtor Rural (PAPP), Programa Nacional de Fortalecimento da Agricultura Familiar (PRONAF) and Programa de Aquisição de Alimentos (PAA). Anchored in the cognitive approach to public policy analysis, the paper examines the ideas that gave rise to these programs, the actors who built them, the negotiation of ideas between them and the institutionalization of these ideas in public policy.
\end{abstract}

Key words: Public policy; Ideas; Family farming.

Doutora no Programa de Pós-Graduação de Ciências Sociais em Desenvolvimento, Agricultura e Sociedade (CPDA/UFRRJ) e pesquisadora no Observatório de Políticas Públicas para a Agricultura (OPPA/CPDA). Este artigo apresenta os resultados parciais da tese de doutoramento, realizada neste Programa de Pós-Graduação. Contato: catiagrisa@yahoo.com.br 


\section{Introdução}

A

s décadas de 1960 e 1970 são consideradas marcos da intervenção do Estado brasileiro na agricultura (Mueller, 2010; Coelho, 2001). Visando transformar o meio rural e modernizar a agricultura, o Estado assumiu de forma explícita o comando do processo de capitalização do campo, conjuntamente com o capital financeiro e industrial. Em termos de política agrícola, sua atuação concentrou-se em cinco instrumentos principais: financiamento da produção por meio da institucionalização do Sistema Nacional de Crédito Rural (SNCR), garantia de preços e comercialização através da Política de Garantia Preços Mínimos (PGPM), transferência de tecnologia e assistência técnica pela Empresa Brasileira de Assistência Técnica e Extensão Rural (EMBRATER), inovações tecnológicas promovidas pela Empresa Brasileira de Pesquisa Agropecuária (EMBRAPA), e garantia de seguro agrícola por meio do Programa de Garantia da Atividade Agropecuária (PROAGRO).

Como esperado, estes instrumentos geraram aumento da produção, promoveram divisas para o desenvolvimento econômico e contribuíram com a política de substituição de importações. Contudo, como afirmam diversos autores, o caráter triplamente seletivo deste conjunto de instrumentos beneficiou apenas um grupo restrito de produtos, agricultores e regiões (Delgado, 2010; Graziano da Silva, 1999, 1996; Kageyama et al, 1990; Kageyama e Graziano da Silva, 1983). Aos agricultores familiares - reconhecidos como produtores de baixa renda, pequenos agricultores ou produtores para a subsistência - couberam, sobretudo, as consequências do processo de modernização: endividamento, desemprego, perda das terras, êxodo rural e agrícola, degradação ambiental etc.

Para minimizar estes resultados e responder às necessidades peculiares deste grupo social, o Estado executou durante os anos 1980 alguns programas específicos e regionalizados para os pequenos produtores. Dentre eles, o Projeto Nordeste, o qual incluía o Programa de Apoio ao Pequeno Produtor Rural (PAPP). Implantado com recursos do Banco Mundial, esse Programa visava melhorais na produção e na comercialização dos agricultores familiares, sendo suas ações aplicadas em vários domínios: geração e difusão de tecnologias, assistência técnica e extensão rural, ações fundiárias, comercialização, abastecimento, recursos hídricos e apoio às comunidades rurais.

Foi somente na metade da década de 1990 que os "pequenos agricultores" tornaram-se "público" efetivo das políticas agrícolas, agora denominados "agricultores familiares". Até este momento não existia nenhuma política com abrangência nacional voltada particularmente a este segmento social (Schneider, Cazella e Mattei, 2004). A criação do Programa Nacional de Fortalecimento da Agricultura Familiar (PRONAF) em 1995, ofertando crédito rural em condições distintas, marcou o reconhecimento do Estado à agricultura familiar e à necessidade de delinear políticas diferenciadas de desenvolvimento rural que contemplassem as suas especificidades socioeconômicas. 
Posteriormente ao PRONAF, outras políticas públicas foram elaboradas com foco nessa mesma categoria social, como, por exemplo, o Seguro da Agricultura Familiar (SEAF), o Programa de Garantia de Preços da Agricultura Familiar (PGPAF) e o Programa Garantia Safra, sendo a maior parte destas políticas complementares ou tributárias das próprias características do PRONAF (Grisa e Wesz Junior, 2010). Uma ação que se diferencia é o Programa de Aquisição de Alimentos da Agricultura Familiar (PAA). Em operação desde 2003, esse programa articula a compra de alimentos produzidos por agricultores familiares com ações de segurança alimentar e nutricional. O governo federal adquire os alimentos a preços de referência e distribui às pessoas em situação de vulnerabilidade social, atendendo igualmente a rede de equipamentos públicos de alimentação e nutrição, instituições socioassistenciais e escolas ou, ainda, a formação de estoques reguladores.

Criados em períodos distintos e operacionalizados a partir de instrumentos diferenciados, esses três programas (PAPP, PRONAF e PAA) compartilham o fato de terem sido concebidos visando especificamente à agricultura familiar. Mas, e quanto às "ideias" que deram origem a essas políticas públicas, são elas diferentes? O que cada uma destas políticas visava para a agricultura familiar? De onde vieram as "ideias" de construir políticas com tais características? Como foi possível a construção destas políticas diferenciadas? Estas são algumas das questões que instigaram a elaboração deste trabalho, questões ainda pouco abordadas pelos pesquisadores que se dedicaram aquelas políticas públicas e dimensão (ideias) igualmente pouco considerada pelos autores brasileiros que analisam as políticas públicas.

Ao acentuar o papel das ideias na construção do PAPP, PRONAF e PAA, este artigo discute com uma abordagem cognitiva de análise de políticas públicas, a qual enfatiza o papel das ideias, crenças, representações sociais e aprendizagem na elaboração das políticas públicas. A ênfase situa-se no modo como os atores compreendem o mundo, interpretam e propõem soluções aos problemas públicos. Como afirma Surel (2000, p. 01), a abordagem cognitiva considera que "as políticas públicas são influenciadas pelas crenças comuns de um conjunto de atores (públicos e privados), as quais definem a maneira como estes atores percebem os problemas públicos e concebem respostas para os mesmos." A partir desta compreensão comum, várias perspectivas buscam trabalhar a relação entre ideias e políticas públicas (Muller, 2008; Jobert e Muller, 1987; Sabatier e Jenkins-Smith, 1999; 1993; Surel, 1995; Hall, 1993; Schmidt e Radaelli, 2004; Radaelli, 2000; Fouilleux, 2011; 2003). Dentre estas, o quadro de análise construído por Bruno Jobert e Ève Fouilleux contribui de modo especial ao objetivo deste trabalho ao acentuar o processo de construção das ideias e a sua emergência como "receitas" públicas.

Esta perspectiva busca reconstruir a trajetória das ideias que levaram à institucionalização das políticas públicas e explicar os processos de mudanças e estabilidade destas a partir das trajetórias. A ênfase recai sobre a atuação de diferentes grupos de atores sociais na produção das ideias, a negociação e a construção de um 
compromisso entre eles, a institucionalização das ideias em políticas públicas e os processos de mudanças a partir da desestabilização dos compromissos entre os atores envolvidos. Além de ser o quadro analítico que fornece instrumentos mais adequados para responder as indagações deste trabalho, esta perspectiva procura superar uma relevante crítica endereçada à abordagem cognitiva, qual seja, a valorização excessiva das variáveis cognitivas, desconsiderando o papel dos interesses e das instituições.

Resultante de pesquisa documental e entrevistas semi-estruturadas ${ }^{1}$, a análise desenvolvida neste artigo organiza-se em cinco seções. A primeira discute brevemente a abordagem cognitiva de políticas públicas aproximando-a ao objeto deste estudo. Os três itens subseqüentes analisam, respectivamente, o processo de construção do PAPP, do PRONAF e do PAA, enfatizando os atores e as ideias que contribuíram nesse processo e o referencial de política pública institucionalizado. Finalmente, são apresentadas algumas considerações sobre análise desenvolvida.

\section{As ideias nos fóruns e nas arenas de política pública: uma aproximação ao objeto de estudo}

Partindo da constatação de que a maioria dos estudos que abordam as ideias tomam-nas como dados a priori, seja como inputs no processo decisório (as ideias dando origem às políticas públicas), seja como sub-produtos do processo decisório (as políticas públicas enquanto fontes de informação e sentidos), Fouilleux (2000) evidencia uma lacuna concernente às modalidades de produção das ideias e sua emergência como receitas de ação pública. Para a autora, é fundamental analisar o processo de produção das ideias, evidenciando os atores que as constroem e como elas são institucionalizadas em políticas públicas. As ideias são, aqui, compreendidas como "um conjunto de representações, quadros de análise e de esquemas de interpretação diversos que fazem sentido através da sua encarnação em comunidades de atores específicos." (Fouilleux, 2000, p. 278).

Ao centrar a análise em ideias "encarnadas" em comunidades de atores, esta perspectiva busca uma articulação entre ideias, instituições e interesses, dimensões geralmente pouco integradas nas análises da abordagem cognitiva. Compreende-se aqui que os interesses são construções sociais que mobilizam crenças e representações, de modo que, para defender interesses, assume-se a necessidade de construir anteriormente representações sobre o objeto (Jobert, 2004). Por sua vez, similarmente a North (1991), as instituições são apreendidas como "regras do jogo" criadas pelos atores e que enquadram suas interações. Isto inclui o quadro mais geral de interação do sistema político (constituição, leis etc. - portanto, instituições exógenas às políticas públicas) e a própria política pública (regulamentos, manuais etc. - instituições endógenas). Os instrumentos de uma política pública são compreendidos como regras definindo quem participa, quando e como. São instituições que se estabilizam após um amplo processo de negociação de ideias, mas que, em razão dos efeitos de 
feed back institucional (Pierson, 2003), também podem afetar a produção de ideias e a natureza dos debates desenvolvidos (Fouilleux, 2003). Deste modo, os atores sociais são "depositários de ideias e interesses, mas igualmente intimamente ligados às instituições em jogo, seja por meio da interiorização (em graus diversos) do quadro institucional no qual interagem, seja por meio da participação contínua na sua fabricação e modificação." (Fouilleux, 2003, p.28).

Três conceitos são importantes para esta perspectiva: fórum de produção de ideias, fórum de comunidades de política pública e arena. Fouilleux (2003; 2000) define fórum como espaços mais ou menos institucionalizados, mais ou menos especializados, regidos por regras e dinâmicas específicas, nos quais grupos de atores debatem diferentes visões de mundo. O fórum de produção de ideias é o espaço onde são produzidas diferentes representações sobre as políticas públicas, as quais variam segundo interesses, identidade, relações de poder e instituições. Além da natureza das ideias manipuladas e produzidas sobre uma mesma política ser diferente entre os fóruns, também são distintos os critérios de aceitabilidade e de coerência do discurso, bem como a evolução das controvérsias no interior dos fóruns. Por sua vez, o fórum de comunidades de política pública é o espaço de reutilização e institucionalização das ideias produzidas pelos fóruns de produção de ideias, onde estas são discutidas, selecionadas, combinadas e institucionalizadas em políticas públicas. Portanto, há circulação de ideias do fórum de produção de ideias para o fórum de comunidades de política pública, constituindo etapas sucessivas em presença de atores distintos. ${ }^{2}$ Todavia, uma vez as idéias institucionalizadas, estas repercutem nos fóruns de produção de idéias, influenciando e orientando o debate (Fouilleux, 2011; 2003).

Aproximando este quadro analítico ao objeto deste trabalho, cinco fóruns de produção de ideias podem ser identificados pela sua influência e participação na elaboração de políticas públicas para a agricultura familiar, quais sejam:

a) fórum científico: tratam-se principalmente de estudiosos do meio rural e das temáticas da agroecologia e da segurança alimentar e nutricional, os quais produzem análises e interpretações que influenciam e subsidiam as mudanças ou a construção de novas políticas públicas para a agricultura familiar. Igualmente integram este grupo as organizações internacionais que apresentam abundante produção analítica e discursiva e que fazem sistematicamente apelo a uma legitimação científica para propor orientações, ações e políticas públicas. O capital político e financeiro desses atores favorece a institucionalização de suas ideias;

b) fórum da comunicação política (também denominado fórum da retórica política): integra os grupos político-partidários que, a cada quatro anos, disputam as eleições. O objetivo destes atores é a conquista e a conservação do poder político, passando pela construção de coalizões, desvalorização dos adversários e argumentações com vistas de convencer os eleitores. A produção de ideias neste fórum toma a forma de programas e discursos eleitorais; 
c) fórum da agricultura familiar: este fórum é representado pelas organizações sindicais e movimentos sociais rurais (CONTAG, FETRAF, MPA, MST etc.) que dialogam, afrontam-se e tentam fazer prevalecer tanto na sua base, quanto no poder público, uma visão do que deve ser a agricultura familiar brasileira. Cada modelo de agricultura proposto está relacionado com uma identidade específica e com interesses a serem defendidos;

d) fórum de segurança alimentar e nutricional: este fórum é composto por organizações não-governamentais, movimentos sociais, intelectuais e sociedade civil organizada que debatem a temática da segurança alimentar e que, principalmente desde a década de 1990, vem propondo ações contra a fome e a insegurança alimentar;

e) fórum agroecológico: compõe-se de agricultores, organizações não-governamentais, organizações e movimentos sociais, profissionais, acadêmicos e pesquisadores que, sobretudo a partir dos anos 1980, passaram a debater o tema da agricultura alternativa/agroecológica, acompanhando e sistematizando experiências e participando dos processos de elaboração e execução das políticas públicas.

É importante notar que muitos atores sociais participam, ao mesmo tempo, de mais de um fórum de produção de ideias. Assim, por exemplo, um membro do fórum da agricultura familiar também pode compor o fórum da comunicação política, ou, um membro do fórum científico pode participar do fórum de segurança alimentar e nutricional. Essa circulação dos atores e ideias entre os fóruns de produção de ideias pode ser justamente um dos fatores explicativos da hegemonia de certas ideias e da sua institucionalização em políticas públicas: as mesmas ideias são defendidas em espaços diferentes, favorecendo que estas se tornem dominantes. Contudo, como aludido acima, é importante considerar que cada fórum de produção de ideias é regulado por interesses e instituições distintas, o que faz com que, embora um ator participe de mais de um fórum simultaneamente, a expressão de suas ideias pode diferenciar-se dependendo do local onde se encontra.

Cada fórum de produção de ideias apresenta dinâmicas peculiares e "referenciais centrais" distintos (Fouilleux, 2003; 2000). "Referencial central" pode ser concebido como um conjunto de ideias e representações específicas que são dominantes em um dado fórum, sendo que estas ideias enquadram os debates, asseguram uma relativa estabilidade nas trocas e permitem aos atores situarem-se e identificarem-se. Por exemplo, o fórum da agricultura familiar produz de forma permanente representações sobre a categoria e as políticas agrícolas e apresenta um referencial que diz respeito a modelos de agricultura (concepções sobre práticas agrícolas e o agricultor familiar); o fórum agroecológico também elabora de forma constante representações sobre modelos de produção agrícola e a agroecologia, e apresenta um referencial 
concernente a modelos de desenvolvimento rural alternativos ao convencional; por sua vez, o fórum da comunicação política geralmente cristaliza seu discurso sobre um tema em momentos críticos (eleições, crises, períodos de mobilização social etc.) e apresenta um referencial do tipo doutrinário ou ideológico; o fórum de segurança alimentar e nutricional produz de modo constante representações sobre a temática e apresenta um referencial concernente à questão alimentar e nutricional, e; o fórum científico produz suas ideias de modo contínuo e organiza-se em torno de um referencial central do tipo paradigmático, no sentido discutido por Kuhn (2003).

Fouilleux (2000) alude que a dinâmica de construção do referencial central nos fóruns de produção de ideias é do tipo "traducional", conforme propõe a sociologia da tradução de Michel Callon. Neste processo, ocorre a imposição de um referencial dominante e a designação de um grupo de atores que se identificam como portavozes do fórum. Os porta-vozes são legitimados para emitirem suas próprias visões de mundo ao exterior como se fossem aquelas do fórum inteiro. “O processo de tradução confere aos grupos vitoriosos uma forte visibilidade e uma forte legitimidade, tornando-os naturalmente os interlocutores privilegiados para o exterior do fórum. A atividade "traducional" está, assim, no centro do mecanismo de produção e visibilidade das ideias tanto no interior quanto no exterior do fórum" (Fouilleux, 2000, p. 281).

Todavia, a construção de um referencial central não impede a existência de vozes dissidentes que o recusam e o desafiam/desestabilizam. A controvérsia é sempre presente nos fóruns de produção de ideias e ela somente não ameaça a estabilidade do referencial central quando os atores dissidentes são marginais, frágeis na construção de aliados (internos e externos ao fórum) e/ou não dispõem de recursos políticos, financeiros, humanos e discursivos para colocar em questão o referencial dominante. Um referencial central pode ser modificado ou substituído, por exemplo, no momento de uma nova eleição ou no surgimento de uma crise (econômica, social, ambiental) no fórum da comunicação política; quando de uma eleição sindical ou troca de direção no caso do fórum da agricultura familiar; ou de uma "revolução científica" no fórum científico.

Compreendida a dinâmica dos fóruns de produção de ideias, é mister discutir o fórum de comunidades de política pública. Este é formado pelos "porta-vozes" dos fóruns da comunicação política, da agricultura familiar, científico, agroecológico e de segurança alimentar e nutricional e pelos gestores e técnicos governamentais atores presentes de forma mais permanente no fórum de comunidades de política pública, sendo menos submissos aos "jogos" eleitorais e incumbidos da importação, aglomeração, recombinação e adaptação das ideias que servem à fabricação de políticas públicas ${ }^{3}$. Assim, enquanto nos fóruns de produção de ideias a população é relativamente homogênea, no fórum de comunidades de política pública a heterogeneidade é expressiva (políticos, intelectuais, profissionais, gestores públicos etc.), tornando inteligível a heterogeneidade das ideias e dos sistemas de 
representação em torno de uma política pública (Fouilleux, 2000). A Figura 1, abaixo, ilustra as interações entre os fóruns de produção de ideias e o fórum de comunidades de política pública.

Figura 1: Trocas e interações políticas entre fóruns na construção das políticas públicas para a agricultura familiar.

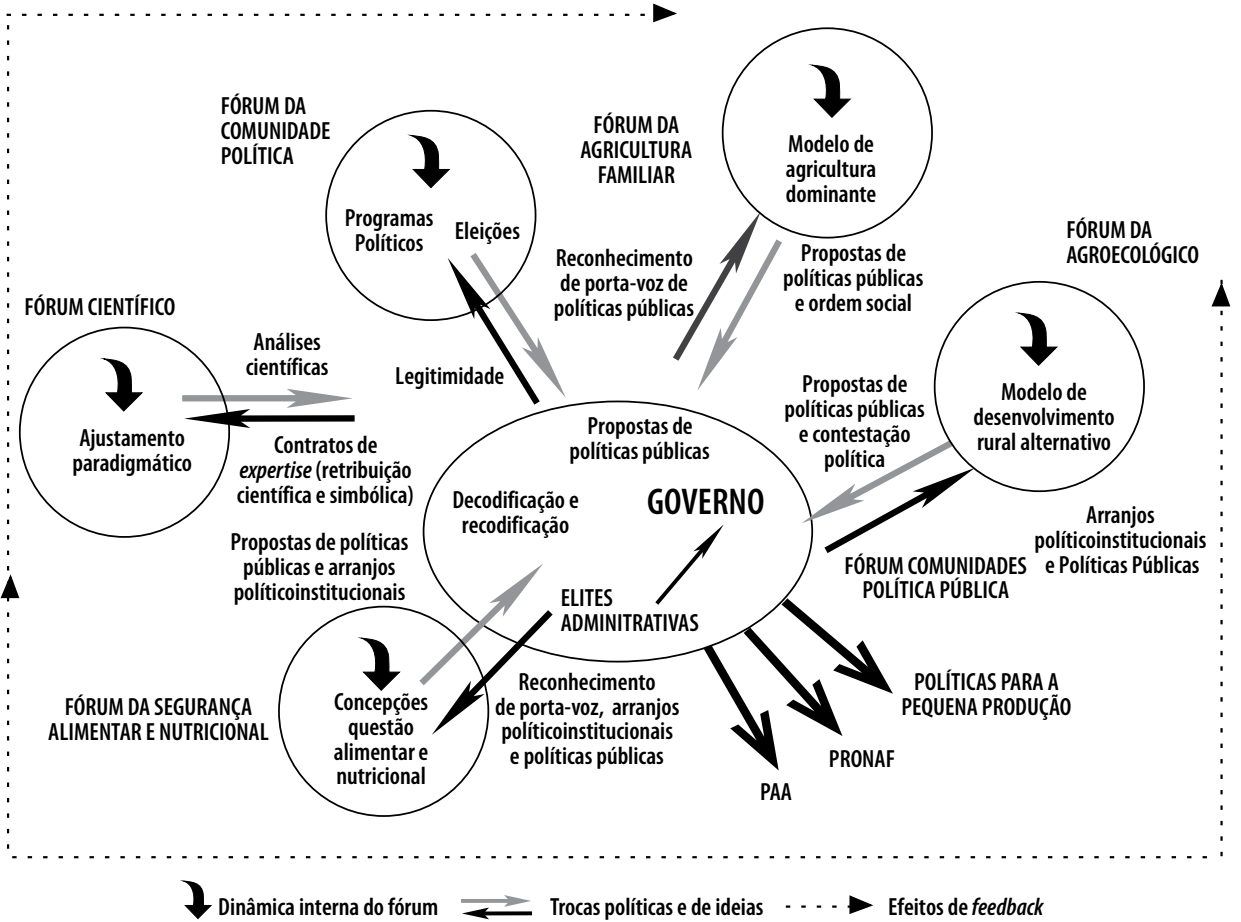

Fonte: Elaboração da autora a partir de Fouilleux (2011; 2003).

A influência de cada fórum de produção de ideias no fórum de comunidades de política pública depende dos recursos que possuem para impor suas ideias e de suas dinâmicas próprias (Fouilleux, 2003). Por exemplo, a relação entre os fóruns da comunicação política e de comunidades de política pública é fortemente institucionalizada. Uma vez o partido ou a coalizão tenha ganhado o processo de tradução no fórum da comunicação política (eleição), ele compõe automaticamente o fórum de comunidades de política pública e passa a ser responsável (juntamente com os gestores e técnicos governamentais) por construir um "compromisso" entre os 
atores que participam neste espaço. As ideias contidas nos programas eleitorais são diretamente importadas para o fórum de comunidades de política pública, todavia, isto não significa a institucionalização direta das mesmas, o que depende das trocas políticas estabelecidas com os porta-vozes dos outros fóruns de produção de ideias em busca da construção de um compromisso entre interesses e concepções heterogêneas. A construção e manutenção deste compromisso confere legitimidade aos porta-vozes do fórum da comunicação política no fórum de comunidades de política pública. Já a interface entre o fórum da agricultura familiar e o fórum de comunidades de política pública é permeada por negociações tensas entre a manutenção da ordem social e a elaboração de políticas públicas, sobretudo distributivas e redistributivas. Por sua vez, a ligação do fórum de comunidades de política pública com o fórum científico envolve demandas de análises científicas concernentes à relação Estado/sociedade e políticas públicas por parte do primeiro, em troca de retribuições financeiras e simbólicas aos experts. A relação entre o fórum de segurança alimentar e o fórum de comunidades de políticas públicas abarca negociações sobre políticas públicas, arranjos políticoinstitucionais, contestação política e reconhecimento dos porta-vozes. Finalmente, a interface entre o fórum agroecológico e o fórum de comunicação política envolve negociações entre, por um lado, a criação e participação em espaços consultivos e deliberativos e a intervenção na elaboração de políticas públicas e, por outro, o apoio político e a crítica social.

A atividade principal do fórum de comunidades de política pública é a produção de suas próprias instituições, especialmente a política pública (Fouilleux, 2000). A produção de uma política pública envolve a construção de um "referencial" que, por sua vez, são os instrumentos da política e seu esquema de organização. Este referencial também pode ser considerado um referencial central, como aludido acima. Todavia, neste caso trata-se de um referencial híbrido, cujos sistemas de representação que o constituem são oriundos de diferentes fóruns de produção de ideias. Nas palavras de Fouilleux (2000, p. 43), o referencial é uma “(...) fotografia da política em um certo momento: um conjunto ordenado de ideias oriundas de diferentes fóruns de produção de ideias, importadas, emendadas, recombinadas e aglomeradas em função dos imperativos próprios ao fórum de comunidades de política pública". O referencial é objeto de negociação permanente entre os protagonistas das trocas políticas, sendo suscetível de inclusões, recortes e transformações em função das relações de força e dos objetivos políticos dos diferentes atores do fórum de comunidades de política pública (cada um procurando impor sua interpretação como referencial). Longe de uma coerência perfeita, o referencial permite explicar a heterogeneidade e as contradições internas suscetíveis de se encontrar em uma política pública, deixando mais transparente a complexidade envolvida.

Diferentemente dos fóruns de produção de ideias, a dinâmica do fórum de comunidades de política pública não é do tipo traducional (Fouilleux, 2000). Aqui, as regras do jogo buscam basicamente um modo de definição da realidade social, 
no qual seja possível obter um "compromisso" entre as partes envolvidas para a elaboração da política pública. Enquanto os atores aderirem a este compromisso, a política pública segue seu curso "normal" (Surel, 1995), não sendo questionada ou alterada em grandes proporções. Todavia, quando este compromisso é ameaçado, o fórum transforma-se em arena: ele entra em uma fase instável de renegociação do compromisso, fase denominada de conjuntura crítica, onde o debate torna-se visível ao grande público, ainda que não facilmente inteligível (Fouilleux, 2000). A vida de um fórum de comunidades de política pública é, assim, ritmada pela alternância de fases de estabilidade e de conjunturas críticas, constituindo dois tipos de dinâmicas das ideias: a) uma configuração "fórum", onde a controvérsia é colocada em latência e há a produção rotineira da política pública, com mudanças marginais e incrementais: novas ideias são institucionalizadas, mas não questionam a economia geral do compromisso e; b) uma configuração "arena" (conjuntura crítica do fórum), em que o compromisso é colocado "em xeque" e as controvérsias emergem e ficam expostas. A instabilidade institucional pode traduzir-se em mudanças de magnitudes maiores ou a criação de uma nova política. A estabilidade é retomada quando há a renovação ou a criação de um novo compromisso.

A crise no fórum de comunidades de política pública pode ter suas origens, seja na tentativa de um ator coletivo acrescer seu poder ou legitimidade alterando o compromisso (estratégia ofensiva); seja na vontade de um ator de modificar o compromisso para conservar sua legitimidade (estratégia defensiva); ou ainda com a chegada de um ator reivindicando o direito de participar da elaboração da política pública (outro caso ofensivo) (Fouilleux, 2003). Mudanças em elementos ou instituições externas e os efeitos de feed back das políticas públicas podem favorecer estes movimentos. Se o compromisso entre os atores não pode ser renovado em decorrência da crise, por conseguinte as trocas políticas e a legitimidade dos atores detentores de poder ficam ameaçadas. A crise termina quando se estabelece um novo equilíbrio, uma situação satisfatória do ponto de vista da repartição dos recursos e da legitimidade de cada um dos atores em função das relações de força existentes (Fouilleux, 2003).

\section{As ideias na construção do PAPP: da modernização da agricultura às políticas para a pequena produção}

Na década de 1960, os porta-vozes do fórum da comunicação política, amparados pelos porta-vozes do fórum científico, delinearam a modernização da agricultura como o "referencial setorial" para a agricultura brasileira, o que se institucionalizou em um conjunto de políticas agrícolas "tradicionais": crédito rural, assistência técnica, seguro, garantia de preços e pesquisa (Delgado, 2005; Gonçalves Neto, 1997; Muller, 2008). A formação deste referencial representou um "ajuste setorial/global" na medida em que, enquanto a economia brasileira projetava industrialização e crescimento interno, 
a agricultura permanecia com baixos níveis tecnológicos e de produção, o que limitaria o próprio desenvolvimento industrial (Muller, 2008; Jobert e Muller, 1987). Assim, a agricultura deveria modernizar-se para continuar cumprindo suas "funções" no processo de desenvolvimento: a) liberar mão-de-obra para a indústria; b) gerar oferta adequada de alimentos baratos, não impactando nos salários; c) produzir matériasprimas para a indústria e adquirir meios de produção oriundos desta; d) elevar as exportações agrícolas para gerar divisas e; e) transferir renda real ao setor urbano. A modernização da base técnica (sem mudanças na estrutura agrária) e a qualificação do capital humano para produção e difusão de tecnologias seriam suficientes para que a agricultura respondesse à demanda do mercado e cumprisse suas funções no desenvolvimento (Delgado, 2005).

Na década de 1970, visando dar seqüência às suas concepções de desenvolvimento e construir um compromisso com o fórum da agricultura familiar ${ }^{4}$ - o qual pouco tinha se beneficiado com a modernização da agricultura -, os porta-vozes do fórum da comunicação política propuseram alguns programas regionalizados que atendiam à pequena produção. Ao mesmo tempo em que buscavam dar continuidade à política de substituição de importações ${ }^{5}$, estes atores reconheceram, por meio do "Plano de Desenvolvimento Econômico e Social" (II PND: 1975-79), o imperativo de desenvolver ações sociais. Havia a necessidade de, mantendo acelerado o crescimento econômico, realizar políticas redistributivas "enquanto o bolo crescia" (Brasil, 1974). Neste sentido, notadamente no que concerne ao setor rural, foram construídos "Programas Especiais" para os pequenos produtores visando ações "substitutivas" à reforma agrária, instrumentos tradicionais de política agrícola e obras de infraestrutura socioeconômica. Atrelado a esta compreensão, somava-se o interesse de "acalmar ou desviar as reivindicações das organizações camponesas" (Sabourin, 2009, p. 144), as quais, embora "contidas" pela ditadura militar, continuaram pautando a reforma agrária e os direitos trabalhistas e realizando mobilizações sociais (Medeiros, 2010; CONTAG, 1973; 1979).

Confluindo com as ideias e os interesses do fórum da comunicação política encontravam-se as ideias e os interesses do Banco Mundial, que financiou muitos dos programas implementados, dentre eles o POLONORDESTE. Este Programa organizavase em torno de Projetos de Desenvolvimento Rural Integrado (PDRI's), selecionando agrupamentos de pequenos agricultores para a intervenção integrada ao nível das unidades de produção (crédito rural, assistência técnica, apoio à comercialização etc.) e ao nível da infraestrutura socioeconômica (rodovias vicinais, eletrificação rural, educação, saúde etc.). Como evidenciaram Delgado (1989) e Wilkinson (1986), em termos gerais, este Programa buscou aplicar o referencial da modernização da agricultura aos pequenos agricultores do Nordeste.

Avaliações negativas do Programa, somadas a um direcionamento maior à redução da pobreza rural pelos porta-vozes do fórum da comunicação política e do Banco Mundial, conduziram à reformulação do POLONORDESTE e à emergência do 
Projeto Nordeste, política aglutinadora de seis programas, dentre os quais se incluiu o PAPP. Este foi criado visando "erradicar a pobreza absoluta no meio rural" por meio do fomento à produção e produtividade (Brasil, 1986). Seu referencial de política pública expressava-se em dois instrumentos: apoio à produção e, principalmente, Apoio às Pequenas Comunidades Rurais (APCR). No primeiro estavam compreendidas ações de intervenção nos recursos hídricos (pequenos projetos de irrigação pública e privada e sistemas simplificados de abastecimento de água nas comunidades camponesas), ações fundiárias (regularização e redistribuição de terra), apoio à comercialização (orientação técnica, aquisição da produção e infraestrutura de apoio), geração e difusão de tecnologias, e crédito rural (custeio, investimento e fundiário). Quanto ao APCR, procurava-se desenvolver a organização social dos pequenos produtores rurais por meio do desenvolvimento de comunidades rurais, de atividades produtivas de caráter coletivo e da melhoria dos equipamentos públicos e comunitários (Delgado, 1989). Tratava-se da abordagem do "desenvolvimento dirigido pelas comunidades" (community driven development), desenvolvida pelo Banco Mundial. Acompanhada pelos governos local e federal, setor privado, sociedade civil ou ONG's, a comunidade rural beneficiava-se com recursos financeiros e tornava-se responsável pela administração e decisão acerca de sua aplicação.

Contudo, segundo algumas avaliações, as ações do PAPP igualmente apresentaram limitações, sendo o APCR o instrumento que apresentou melhores resultados (Zyl et al., 1995; Banco Mundial, 1994; Delgado, 1989). Conforme Delgado (1989, p. 129), "Para muitos pequenos produtores, inclusive, o PAPP se confunde com o APCR". Com efeito, o referencial do PAPP foi reformulado em 1993 e o apoio às comunidades rurais tornou-se o instrumento central do Programa. Os projetos desenvolvidos por meio dos APCR tornaram-se os principais instrumentos no "alívio" à pobreza rural e, por conseguinte, a redução da pobreza tornou-se central no referencial de política pública para a pequena produção no Nordeste - acompanhando o próprio direcionamento do Banco Mundial que, na década de 1990, intensificou as estratégias de redução da pobreza (Pereira, 2009; Speranza, 2005). ${ }^{6}$ À medida que as avaliações do PAPP foram realizadas, o "alívio" à pobreza dos pequenos produtores rurais tornou-se, de modo cada vez mais explícito, o referencial de política pública para este segmento. Não por acaso, em 1995 o PAPP passou a denominar-se Programa de Combate à Pobreza Rural (PCPR), vigente ainda atualmente (Soares, 1996; Souza Filho, Buainain e Silveira, 2006).

É importante ressaltar que a construção destas políticas para a pequena produção (POLONORDESTE e PAPP) não contou com as ideias do fórum da agricultura familiar. Ainda que, no caso do PAPP, os pequenos produtores tenham participado na sua execução, os mesmos não puderam intervir na elaboração cognitiva e normativa da política e seus instrumentos. A ausência do fórum da agricultura familiar no fórum de comunidades de política pública deve-se, por um lado, ao contexto político institucional que excluía a sua participação e, por outro, às ideias de seus representantes, as quais divergiam daquelas dos demais fóruns de produção de ideias que integravam este 
espaço no que concerne ao papel da pequena produção no desenvolvimento do país e os instrumentos de política agrícola e agrária necessários a sua reprodução social. A defesa da reforma agrária, de políticas diferenciadas de desenvolvimento rural, da legislação trabalhista e as críticas ao regime ditatorial eram constantes nas reivindicações do fórum da agricultura familiar, o qual começou a ter maior espaço no fórum de comunidades de política pública no final da década de 1980, com o processo da constituinte.

\section{As ideias na construção do PRONAF: da pequena produção à agricultura familiar}

A partir da segunda metade da década de 1980, dois processos alteraram o Estado brasileiro e a ordem social e econômica, afetando também a agricultura familiar: a democratização política, mais expressiva no final dos anos 1980, e a liberalização econômica, aguda nos anos 1990.

O processo de abertura democrática possibilitou um "intenso movimento de rearticulação e florescimento de novas organizações na sociedade civil" (Santos, 2011, p.79). No âmbito da agricultura familiar destacaram-se, por exemplo, as mudanças na forma de atuação da CONTAG, a constituição da CUT e do Departamento Nacional de Trabalhadores Rurais (DNTR), a criação do MST, do Conselho Nacional de Seringueiros (CNS) e do Movimento de Atingidos por Barragens (MAB). Essas organizações passaram a ter maior visibilidade política e a reivindicar a participação do fórum da agricultura familiar no fórum de comunidades de política pública. Ainda que com objetivos ou ênfases distintas, as ações destes atores tornaram visíveis as precárias condições de reprodução social dos pequenos produtorese, cada vez mais, reclamaram a intervenção do Estado na construção de políticas públicas adequadas às suas particularidades. Isso se tornou evidente nos debates da constituinte e na construção das Leis Agrícola e Agrária, onde esses atores disputaram a construção de políticas públicas com o que poderia ser denominado fórum da agricultura patronal.

Por sua vez, o processo de liberalização econômica - construído a partir das ideias de um novo referencial global (o neoliberalismo) para enfrentar a crise política e financeira das décadas de 1980 e 1990 - impôs novas estratégias e instrumentos para a ação governamental. Redução da intervenção estatal, desregulamentação das atividades econômicas, "desmonte" dos instrumentos de política agrícola construídos nas décadas anteriores, privatização de companhias estatais, liberalização dos mercados e criação do Mercosul foram algumas das medidas sugeridas por este novo referencial global, as quais foram adotadas pelos porta-vozes do fórum da comunicação política no Brasil. Estas medidas afetaram as condições de reprodução social e econômica dos agricultores familiares, que já sentiam as consequências do "lado indesejável" da modernização da agricultura (Graziano da Silva, 1999). Contrapondo-se a esse contexto, e favorecidos pela abertura política, o fórum da agricultura familiar 
passou a adotar estratégias propositivas em contraposição a uma postura crítica e reivindicatória até então prevalecente (Picolotto, 2011; Favareto, 2006).

Um evento simbólico concerniu à realização do I Grito da Terra Brasil em 1994, uma mobilização nacional que unificou diferentes organizações do fórum da agricultura familiar (DNTR/CUT, CONTAG, MST, MAB, CNS, Coordenação das Articulações dos Povos Indígenas do Brasil e Movimento Nacional de Pescadores), mesmo existindo ideias dissidentes no interior do fórum. A "Pauta Nacional de Reivindicações" desta mobilização organizava-se em torno de sete eixos: reforma agrária, política agrícola, direitos sociais e trabalhistas, previdência social, saúde e segurança no trabalho, política energética e meio ambiente (Grito da Terra Brasil, 1994). No que concerne à política agrícola, as demandas dirigiam-se à construção de crédito rural diferenciado aos pequenos agricultores (recursos exclusivos, juros e prazos de pagamentos específicos); institucionalização de uma nova classificação de pequeno produtor; garantias de comercialização; políticas específicas para a borracha, babaçu e pescadores artesanais; suspensão e renegociação das dívidas; ampliação do prazo para a desregulamentação das tarifas de importação do setor primário para o Mercosul; destinação de no mínimo 30\% dos Fundos Constitucionais para a "pequena agricultura familiar"; além de outras demandas específicas (Grito da Terra Brasil, 1994, p.09). Como observa Bittencourt (2003, p. 101), dentre as reivindicações destacava-se, sobretudo, a demanda por crédito rural diferenciado:

Entre 1992 e 1996, apesar das pautas de reivindicações incluírem assistência técnica, infraestrutura, meio ambiente e tecnologia, durante as negociações estes temas acabavam colocados em segundo plano. $O$ ponto central era a demanda por crédito rural diferenciado e os argumentos utilizados pelas lideranças sindicais na época eram: "não podemos discutir assistência técnica se não tivermos crédito para produzir"; "não podemos discutir alternativas de diversificação se não tivermos crédito"; "o meio ambiente é importante, mas precisamos ter renda para discutir a sua preservação". O crédito era, portanto o foco central para a grande maioria das mobilizações dos agricultores familiares.

Paralelamente às mobilizações do fórum da agricultura familiar, uma mudança paradigmática acontecia no fórum científico. Diferentemente de "um final trágico" ou de subordinação às condições capitalistas de produção, como apontavam os estudos rurais das décadas de 1960 e 1970, o fórum científico passou a ressaltar as diferentes estratégias dereproduçãosocial daagriculturafamiliar, desvelando sua capacidade de resiliência e inovação, assim como seu papel estratégico nos países desenvolvidos e sociedades contemporâneas. Os trabalhos de Veiga (1991), Abramovay (1992) e Lamarche (1993; 1999) foram emblemáticos neste sentido, contribuindo para a substituição do conceito de "pequena produção" em prol da noção de "agricultura familiar".

Outros dois grupos de estudos também contribuíram nesta mudança paradigmática, os quais apresentaram uma relação mais próxima com o fórum da comunicação política e o fórum de comunidades de política pública. Trata-se do relatório "Brazil, 
the management of agriculture, rural development and natural resources", elaborado pelo Banco Mundial, e dos trabalhos do Projeto UTF/BRA/036/BRA, estes resultantes de um convênio de cooperação técnica entre a Organização das Nações Unidas para a Alimentação e Agricultura (FAO) e o Instituto de Colonização e Reforma Agrária (INCRA). O relatório do Banco Mundial reconheceu a relevância da agricultura familiar na produção de alimentos e na geração de empregos nos países desenvolvidos e no Brasil, recomendou a redução da intervenção do Estado na agricultura e sugeriu que este interviesse apenas nas falhas de mercado e em políticas ambientais e de redução da pobreza (Banco Mundial, 1994). Já os relatórios FAO/INCRA (1994; 1996) contribuíram à definição de agricultura familiar, reconheceram numérica e economicamente a relevância desta categoria social, classificaram os estabelecimentos rurais brasileiros (patronal e familiar) e a própria agricultura familiar ("consolidada", "periférica" e "em transição") e propuseram um conjunto de políticas para a construção de uma nova estratégia de desenvolvimento rural.

As idéias do fórum científico e os "gritos" do fórum da agricultura familiar ecoaram no fórum da comunicação política. Alguns porta-vozes desse fórum e alguns gestores públicos reconheciam a importância econômica da agricultura familiar e discutiam a construçãode políticas diferenciadas para estesegmento.Comoaludiuumentrevistado, esses atores "(...) entendiam ser importante o desenvolvimento, o fortalecimento da agricultura familiar por entender sua importância, seja no desenvolvimento local, seja no [desenvolvimento] geral do campo (...)." Além disto, outros fatores favoreceram para que a construção de uma política diferenciada para a agricultura familiar entrasse na agenda pública, quais sejam: a) alguns porta-vozes do fórum da agricultura familiar eram filiados ao principal partido dos porta-vozes do fórum da comunicação política e esta circulação dos atores em diferentes fóruns de produção de ideias permitiu que as "mesmas" ideias fossem tratadas e "defendidas" em diferentes espaços, favorecendo que essas se tornassem dominantes no fórum de comunidades de política pública; b) vivia-se um momento de "agitação" social no meio rural decorrente das mobilizações dos Gritos da Terra Brasil e das lutas do MST e, deste modo, a construção de uma política diferenciada poderia servir para "acalmar" e manter a ordem social no campo, e; c) havia interesses dos porta-vozes do principal partido do fórum da comunicação política em manter relação com o sindicalismo rural.

Acordada a construção de uma política diferenciada para a agricultura familiar entre os porta-vozes do fórum da comunicação política, os debates seguiram em torno da definição dos objetivos, instrumentos e público beneficiário, ou seja, o referencial da política pública. As ideias de distintos fóruns de produção de ideias - fórum da agricultura familiar, científico e da comunicação política - foram apresentadas, selecionadas, negociadas e institucionalizadas no fórum de comunidades de política pública, resultando na criação do Programa Nacional de Fortalecimento da Agricultura Familiar (PRONAF), em 1995. Ainda que tenham ocorrido conflitos e divergências de ideias - principalmente em torno da definição do público beneficiário (o agricultor 
familiar) -, foi possível a construção de um compromisso entre os atores sociais envolvidos, permitindo a passagem de um período de instabilidade e debate público (conjuntura crítica - condição arena) para um momento de estabilidade na política pública (condição fórum).

O compromisso estabeleceu-se em torno de um referencial de política pública que visava atuar no financiamento da produção agrícola (crédito rural), infraestruturas e serviços municipais, na capacitação e profissionalização dos agricultores familiares e na negociação de políticas públicas com órgãos setoriais. Privilegiavam-se os agricultores familiares "em transição", orientados por estratégias de reprodução social basicamente agrícola e não havia, ao menos explicitamente, proposições de um modelo de produção agrícola distinto daquele vigente até então - baseado na especialização agrícola, em pacotes tecnológicos e na "externalização" produtiva - e que provocara importantes danos sociais e ambientais (Silva e Martins, 2010; Carneiro, 1997). Sinalizava-se, deste modo, para a construção de um referencial produtivista do PRONAF, posteriormente ratificado pelo fórum científico (Aquino e Schneider, 2010; Shiki, 2010; Sabourin, 2009; Toledo, 2009; Mattei, 2006; Gazola e Schneider, 2005; Campos e Cardoso, 2004; Kageyama, 2003; Neuman e Ferreira, 2002) e reconhecido atualmente pelos fóruns da comunicação política e da agricultura familiar, como pode ser observado nos depoimentos abaixo de representantes dos respectivos fóruns de produção de ideias. Não raro, os recursos do PRONAF têm beneficiado os agricultores familiares mais capitalizados, geralmente localizados no Sul do Brasil e produtores de commodities agrícolas (Grisa, 2012; Aquino e Schneider, 2010; Mattei, 2006; Ibase, 2006; Kageyama, 2003;).

Quando se começou a discussão do PRONAF, o discurso geral era um discurso muito mais amplo por parte dos movimentos, questionando o uso abusivo de agrotóxicos, a monocultura, mas quando ia para o concreto se transformava em crédito. Então se tinha uma discussão maior, mas não tinha política ou propostas efetivas para estas mudanças. Quando se obteve o PRONAF, muito da discussão acabou se esvaziando, por quê? Porque as pessoas queriam crédito e você ia ver para que as pessoas estavam usando o crédito era exatamente para o modelo tradicional de monocultura, uso dos insumos da mesma forma que sempre se questionou.

Se você olhar, uma coisa é quando o movimento discute uma coisa de longo prazo, aí este debate de desenvolvimento sustentável, de modelo de produção aparece com muita clareza; quando se vai para o imediato isto some, porque tem a tendência de buscar aquilo que é mais imediato. Então este debate sobre o crédito está inserido neste debate de que desenvolvimento nós queremos. Agora, quando você vai negociar o crédito em específico, esta dinâmica do desenvolvimento some um pouco e muito mais por parte do governo, porque você tem dificuldades de implantar de cara, ou seja, de uma forma intensiva e momentânea uma proposta mais geral. O problema é que, às vezes, o imediato te faz esquecer o de longo prazo, este é um problema para os movimentos. O pessoal discute um modelo de desenvolvimento, mas quando a soja transgênica é afetada pela seca, você vai discutir que este povo precisa ser amparado por políticas. É uma contradição. Então, quando o PRONAF vai ser implantado, acho que faltou um debate mais profundo. O que o governo faz? Pega o modelo de crédito tradicional e faz 
uma adequação a uma demanda de uma política diferenciada. O PRONAF é importante, mas é uma cópia do modelo de crédito tradicional, por produto...

Várias mudanças ocorreram no referencial do PRONAF após a institucionalização em 1995. Estas modificações decorreram do "aprendizado orientado pelas políticas públicas" (Sabatier e Jenkins-Smith, 1999; 1993) e/ou de alterações nas relações políticas no fórum de comunidades de política pública, envolvendo mais ou menos conflitos e dialogando em diferentes graus com o referencial institucionalizado. Duas mudanças serão aqui elucidadas, tanto em virtude da importância das alterações que propuseram ao referencial do Programa, quanto por ilustrarem elementos da abordagem cognitiva de políticas pública.

Visando atender os agricultores familiares que enfrentavam dificuldades para acessar o Programa, em 1997 foi criada uma linha especial de crédito de custeio do PRONAF, usualmente designado “Pronafinho". Conforme Abramovay e Piketty (2005, p. 62), "criou-se uma nova linha de crédito no interior do PRONAF voltada a agricultores bem próximos da linha de pobreza, ou seja, em média, um terço do nível de renda bruta dos primeiros beneficiários do Programa." Tratava-se de um público mais próximo aos "periféricos", segundo classificações dos Relatórios FAO/INCRA, diferindo das concepções originais do PRONAF.

A ideia de construir o Pronafinho emergiu do fórum da agricultura familiar, nomeadamente entre agricultores familiares que viriam a constituir, em dezembro de 1997, em Brasília, o Movimento dos Pequenos Agricultores (MPA). Ambos, o movimento social e o Pronafinho, resultaram das mobilizações realizadas no início de 1996 associadas à estiagem que assolava o Rio Grande do Sul (Picolotto, 2011; Cadoná, 2004). Essas mobilizações revelaram-se espaços profícuos para a discussão e demanda de políticas públicas mais adequadas às especificidades de segmentos da agricultura familiar e, ao mesmo tempo, para apontar a necessidade de estabelecer outro movimento social que não se organizaria a partir da estrutura sindical, dadas as críticas que esses atores apresentavam à atuação da CONTAG e da CUT.

A emergência deste novo ator coletivo (que alguns meses depois constituiu o MPA) e a participação desse no fórum de comunidades de política pública, questionando o referencial do PRONAF, desestabilizou o compromisso entre os atores sociais envolvidos na construção e na implementação do Programa e transformou o fórum de comunidades de política pública em arena. Estes agricultores familiares haviam ganhado projeção pública, sendo necessário considerar as suas ideias e interpretações sobre a agricultura familiar e políticas públicas. Abriu-se, deste modo, o processo de negociação e seleção de algumas ideias, resultando na emergência do Pronafinho em outubro de 1997.

Assim, pode-se afirmar que a criação do Pronafinho marcou a presença de ideias distintas sobre o PRONAF e sobre o próprio fórum da agricultura familiar, sendo estas representações encarnadas sobretudo no MPA. Ao mesmo tempo em que reivindicavam a construção de um PRONAF diferenciado para um público 
específico, estes "novos" porta-vozes do fórum da agricultura familiar (re)construíram representações diferenciadas sobre a sua própria identidade e a relação com o mundo, redefinindo suas práticas e ações.

A outra mudança refere-se à criação das linhas PRONAF agroecologia e PRONAF semi-árido. A criação destas está relacionada com a alteração nos porta-vozes do fórum da comunicação política em 2003. Mais que uma troca de presidente, esse período marca mudanças importantes no "referencial global" (Muller, 2008), traduzindo-se em alterações no papel do Estado, no direcionamento das políticas públicas, nos temas em pauta, na relação com os movimentos sociais e sociedade civil em geral etc. Dentre as mudanças mais significativas para os interesses deste trabalho, destacamse a prioridade dada aos temas da fome e da segurança alimentar e nutricional e a possibilidade de diálogo entre o governo e setores que até então encontravam dificuldades em participar da elaboração de políticas públicas, como eram os casos dos fóruns agroecológico e de segurança alimentar e nutricional.

A partir da crítica ao modelo convencional de produção financiado pelo Programa, o fórum agroecológico elaborou propostas para o financiamento da transição agroecológica visando alterar o referencial do PRONAF. Resultado das ideias desse fórum e das negociações no fórum de comunidades de política pública, as linhas PRONAF agroecologia e semi-árido foram criadas para incentivar projetos de produção agroecológica ou a transição para uma agricultura sustentável. Nas palavras de Weid (2006, p.19),

Em 2003, a Articulação Nacional de Agroecologia (ANA), representada pelo seu Grupo de Trabalho sobre Financiamento da Produção, manteve contatos regulares com técnicos e dirigentes do PRONAF visando facilitar o acesso dos agricultores ecológicos e, sobretudo, daqueles em vias de transição agroecológica aos recursos governamentais destinados ao custeio e ao investimento. Como resultado, foram criadas duas modalidades de crédito inovadoras conhecidas como PRONAF Agroecologia e PRONAF Semi-Árido. Além disso, consolidaram-se normas que abrem a possibilidade de emprego das modalidades de PRONAF pré-existentes para o financiamento de projetos com o enfoque agroecológico.

Todavia, é mister ressaltar que o PRONAF Agroecologia e Semi-árido foram e são marginais no interior do Programa. De acordo com Magalhães (2010), no ano agrícola 2007/2008 foram realizados apenas 191 contratos do PRONAF Agroecologia, o que representa $0,01 \%$ dos contratos totais do Programa. Neste sentido, ainda que a criação destas linhas produza alterações no referencial de política pública, até o momento estas não se traduziram em mudanças expressivas na implementação do Programa.

\section{As ideias na construção do PAA: do enfoque setorial à segurança alimentar}

A construção do PAA teve início com uma relevante mudança no fórum da comunicação política. Como mencionado acima, em 2002, Luis Inácio Lula da Silva 
foi eleito presidente da república e principal porta-voz deste fórum. Esta mudança permitiu que atores, até então marginais no interior do fórum da comunicação política, se tornassem dominantes e desfrutassem de maiores oportunidades para a institucionalização de suas ideias. Esses atores já vinham propondo e disputando a elaboração de políticas relacionadas à agricultura familiar e à segurança alimentar e nutricional desde o final da década de 1980. São emblemáticos, neste sentido, o documento "Política Nacional de Segurança Alimentar" elaborado pelo Governo Paralelo7 em 1991 e apresentado ao Presidente da República da época, e o "Projeto Fome Zero: uma proposta de Política de Segurança Alimentar para o Brasil", organizado pelo Instituto Cidadania em 2001.

Em ambos os documentos foram propostas políticas de geração de emprego, recuperação de salários e expansão da produção alimentar visando promover a segurança alimentar e nutricional no Brasil. Dentre essas políticas, encontravam-se medidas de incentivo à produção agrícola, políticas de comercialização e promoção de mercados institucionais, ações de distribuição e consumo de alimentos, medidas emergenciais de combate à fome e a (re)criação do Conselho Nacional de Segurança Alimentar e Nutricional (CONSEA) (Instituto Cidadania, 2001; Governo Paralelo, 1991). A mudança nas relações de poder no fórum da comunicação política em 2002 possibilitou que essas ideias encontrassem maior espaço de institucionalização. Não por acaso, o combate à fome e o "Programa Fome Zero" tornaram-se prioridades no primeiro mandato do Governo Lula e um de seus primeiros atos foi restituir o CONSEA, o qual havia sido criado ainda em 1993, mas extinto no início do governo Fernando Henrique Cardoso quando da criação do Programa Comunidade Solidária.

Como igualmente mencionado na seção anterior, a mudança no fórum da comunicação política e a própria recriação do CONSEA permitiram a participação mais ativa de novos atores no fórum de comunidades de política pública. Isso também se verificou em relação ao fórum de segurança alimentar e nutricional, cujos principais atores vinham discutindo e buscando intervir nas políticas públicas desde o início da década de 1990. O movimento "Ação da cidadania contra a fome e a miséria e pela vida" (1992); a"Campanha Nacional de Combate à Fome" (1993); as mobilizações para a criação do CONSEA (1993); a realização da I Conferência Nacional de Segurança Alimentar e Nutricional (1994); a criação do Fórum Brasileiro de Soberania e Segurança Alimentar e Nutricional (1998) e a recriação do CONSEA (2003) são exemplos de ações que tiveram o protagonismo de representantes do fórum de segurança alimentar e nutricional e foram espaços onde estes construíram elaborações sobre políticas contra a fome, de abastecimento e de segurança alimentar e nutricional para o Brasil. Com a recriação do CONSEA, a participação dos atores e das ideias do fórum de segurança alimentar na formulação e implantação das políticas públicas foi intensificada, destacando-se a participação destes na construção do PAA. Como afirmou Menezes (2010, p.253), "o CONSEA não foi apenas a instância onde foi gerado o Programa, mas permanente espaço de acompanhamento e formulação de propostas para seu aperfeiçoamento." 
Dialogando e/ou participando simultaneamente dos fóruns da comunicação política e da segurança alimentar e nutricional encontravam-se os representantes do fórum científico. Alguns se dedicavam principalmente ao tema da fome, outros à interface entre o agrícola/agrário e a segurança alimentar, e havia ainda aqueles que discutiam especialmente os aspectos nutricionais da questão alimentar. Não raro, todos abordavam a construção de políticas públicas sob estes enfoques. Dentre os principais subsídios deste fórum de produção de ideias para o objeto deste trabalho destacam-se: a interpretação que a fome é expressão biológica de causas sociais, econômicas e políticas; o dimensionamento e o mapeamento da fome no Brasil; a constatação de que, para além da produção agrícola, o acesso aos alimentos é uma dimensão fundamental para a segurança alimentar e nutricional; as análises sobre a importância da regulação pública das atividades econômicas, em especial aquelas do setor agroalimentar, para a segurança alimentar e nutricional e; a afirmação da relevância da agricultura familiar no desenvolvimento do país e na promoção da segurança alimentar (Maluf, 2001; Belik, Graziano da Silva e Takagi, 2001; Pessanha, 1998; Maluf, Menezes e Valente, 1996; Peliano, 1993; Castro, 1946). Muitas destas ideias encontraram eco no fórum de comunidades de política públicas a partir de 2002. Na realidade, com a mudança no fórum da comunicação política, alguns membros do fórum científico assumiram cargos políticos importantes no governo ou tiveram participação ativa em outros espaços políticos, como, por exemplo, no CONSEA, favorecendo a institucionalização de algumas destas ideias.

Também somaram a este contexto as ideias oriundas do fórum da agricultura familiar. Desde a década de 1970, as reivindicações pela garantia de preços mínimos, a comercialização dos produtos agrícolas e a formação de estoques públicos são recorrentes nos documentos de representantes do fórum da agricultura familiar. No ensejo do governo Lula, essas demandas foram reiteradas e incluída a reivindicação de aquisição de alimentos produzidos por esta categoria social para o atendimento do Programa Fome Zero. Se, por um lado, essas ideias caminharam ao encontro do referencial de política pública institucionalizado no PAA, por outro, é importante ressaltar que, desde meados da década de 1990, a principal reivindicação deste fórum de produção de ideias em termos de política agrícola concerne ao PRONAF, considerado "a mola mestra da valorização do setor" (CONTAG, 2001, p. 34). Ainda que o fórum da agricultura familiar tenha participado na elaboração deste Programa por meio de seus representantes no CONSEA e embora a recorrência dos temas da comercialização e abastecimento alimentar nas suas reivindicações, a construção do PAA, diferentemente do PRONAF, não partiu deste fórum de produção de ideias, não obstante as ideias destes atores tenham sido incorporadas no fórum de comunidades de política pública.

De acordo com Muller (2007), os movimentos sociais e sindicais da agricultura familiar tiveram uma participação "tímida" nos anos iniciais do Programa, seja porque se tratava de"projetos pilotos" que incitavam pouca mobilização social, seja porque prioriza- 
vam a pauta do crédito rural. Posteriormente, com a expansão do Programa e exposição de seus resultados, o fórum da agricultura familiar tornou-se um dos principais atores no monitoramento, defesa e proposição de mudanças/adequações no PAA.

Conforme já demonstrado na seção anterior, a partir de 2002, o fórum agroecológico também encontrou maior espaço para apresentar suas ideias sobre modelos de desenvolvimento rural alternativos, seja por meio da participação em espaços consultivos e deliberativos (por exemplo, o CONSEA e o Conselho Nacional de Desenvolvimento Rural Sustentável - CONDRAF), seja em negociações diretas com os representantes do fórum da comunicação política e gestores públicos. O conteúdo da Carta Política do I Encontro Nacional de Agroecologia (ENA), realizado em 2002, elucida algumas das ideias defendidas pelo fórum agroecológico. Nessa, é reiterado que a construção do desenvolvimento rural sustentável passa necessariamente pela priorização da agricultura familiar; ressalta-se a necessidade de financiar "processos descentralizados de armazenamento, beneficiamento, transformação e comercialização de produtos, agregando valor, gerando renda e conservando emprego para as famílias produtoras e dinamizando economias locais"; atribui-se ao Estado a proteção da produção familiar face à competição presente nos mercados globalizados, mediante política de preços mínimos e de aquisição de produtos da produção familiar agroecológica; reafirma-se que a produção agroecológica não se destina a nichos de consumidores, podendo, com políticas públicas adequadas, alimentar a população brasileira; afirma-se as sementes como patrimônio da humanidade; argumenta-se que "ao induzir à especialização produtiva e ao progressivo desaparecimento de variedades e raças locais, os pacotes técnicos disseminados fragilizam o equilíbrio ecológico dos sistemas produtivos, gerando um círculo vicioso no qual a degradação ambiental leva à crescente intensificação do uso de agroquímicos e vice-versa"; manifesta-se à favor da biodiversidade e da diversificação produtiva, e; defende-se uma mudança na matriz tecnológica da agricultura brasileira pautada pela agroecologia (ENA, 2002). Muitas dessas ideias construídas pelo fórum agroecológico confluíam com aquelas aludidas por outros fóruns de produção de ideias citados acima, contribuindo, posteriormente, na construção e institucionalização do PAA. Refletindo este processo e exemplificando a incorporação das ideias deste fórum, a partir de 2004, o PAA oficializa o apoio à agroecologia por meio do acréscimo de $30 \%$ nos preços de referência para os produtos agroecológicos ou orgânicos.

Tão logo o CONSEA foi restabelecido em 2003, o mesmo começou a discutir diretrizes para as ações na área de alimentação e nutrição, incluindo proposições na interface entre agricultura familiar e segurança alimentar. Representantes dos diferentes fóruns de produção de ideias mencionados acima faziam-se presentes neste espaço e defendiam suas concepções sobre SAN e agricultura familiar. Um dos primeiros trabalhos do CONSEA foi o documento "Diretrizes de Segurança Alimentar e do Desenvolvimento Agrário para o Plano Safra - 2003/2004" (Subsídios Técnicos do CONSEA), elaborado em fevereiro de 2003 por um grupo de trabalho formado 
pelo Ministério Extraordinário de Segurança Alimentar e Combate à Fome, Ministério do Desenvolvimento Agrário, Companhia Nacional de Abastecimento e Instituto de Pesquisa Econômica Aplicada. Fazendo uso de uma "narrativa" (Radaelli, 2000) que afirmava a ampliação da demanda de alimentos pelo Programa Fome Zero e, portanto, a possível elevação dos preços ao consumidor, este documento propôs a constituição de um Plano Safra específico para a agricultura familiar, tendo em vista sua importância social, econômica, ambiental e para a segurança alimentar. Ressaltava-se a necessidade de articular a subvenção ao consumo com o apoio à agricultura familiar, o que culminou na criação do PAA em julho de 2003.

É importante destacar que o processo de institucionalização das ideias do PAA, notadamente a construção das suas modalidades, contou com a contribuição de gestores e técnicos governamentais, sobretudo daqueles vinculados à CONAB, os quais traziam consigo a bagagem de outras experiências e, por meio do processo de aprendizado orientado pelas políticas públicas, contribuíram com a construção do Programa. Assim, foram as ideias e o acúmulo histórico dos fóruns da comunicação política, de segurança alimentar e nutricional, científico, da agricultura familiar e agroecológico, com a contribuição de gestores e técnicos governamentais, que possibilitaram a construção do PAA. Como mencionou um entrevistado, "não foi por acaso que o primeiro ato público do governo Lula foi reinstalar o CONSEA e que um dos primeiros atos do CONSEA foi o PAA."

Resultado da negociação de ideias e de interesses no fórum de comunidades de política pública, o PAA é a primeira política nacional para a agricultura familiar que se articula com a política de segurança alimentar e nutricional. Disposto atualmente em cinco modalidades, este Programa visa (i) o estímulo a redes locais de produção e distribuição de alimentos oriundos da agricultura familiar para populações em insegurança alimentar; (ii) a regulação de preços por meio da compra de produtos destinados à formação de estoques públicos; (iii) a aquisição de alimentos da safra vigente para serem estocados e, posteriormente, comercializados pelas próprias organizações sociais que podem, com isso, comercializar sua produção em condições mais favoráveis, e; (iv) a compra e doação de leite a famílias em situação de vulnerabilidade social através de um circuito público de distribuição. Tratase da construção de um referencial de política pública para a agricultura familiar identificado com o enfoque da segurança alimentar e nutricional, o que implica em definições sobre quem produzirá, o que será produzido, o modo como vai fazê-lo e para quem. Como mencionou um entrevistado do fórum da segurança alimentar e nutricional, "O PAA tem tudo para inaugurar algo completamente inovador, que é fazer o encontro da política de segurança alimentar com a política agrícola. Para isto é preciso que você tenha uma determinada visão de segurança alimentar e de política agrícola e uma determinada visão de inter-institucionalidade." Com efeito, o apoio à agricultura familiar, o estímulo a produções agroecológicas e diversificadas, a incitação ao resgate, produção e consumo de alimentos locais, e o atendimento a pessoas em situação de 
vulnerabilidade social são elementos considerados no PAA e que vão ao encontro do enfoque da segurança alimentar e nutricional.

Após sua institucionalização em 2003, algumas mudanças ocorreram no PAA, sendo que a maior parte delas traduziu-se em alterações marginais e incrementais, não ameaçando o compromisso estabelecido entre os atores no fórum de comunidades de política pública. A extinção da modalidade Compra Antecipada é um exemplo de mudança que transformou o fórum de comunidades de política pública em arena. Em razão de resultados inesperados e como estratégia defensiva, alguns porta-vozes do fórum da comunicação política reivindicaram o fim da modalidade. Ainda que representantes dos demais fóruns de produção de ideias tenham se manifestado contrários a esta mudança, a mesma foi efetivada, sendo ainda hoje um tema controverso no fórum de comunidades de política pública.

\section{Considerações fincis}

Como discutido acima, embora tenham sido construídos visando à agricultura familiar, o PAPP, o PRONAF e o PAA apresentam referenciais de política pública diferenciados. Formulados em distintos momentos históricos por diferentes atores sociais, esses Programas responderam a objetivos diversos para a agricultura familiar.

Erigido no início da redemocratização do país a partir de ideias e interesses dos porta-vozes dos fóruns da comunicação política e científico, o PAPP emergiu de uma tentativa "frustrada" (POLONORDESTE) de aplicar o referencial da modernização da agricultura para o segmento dos pequenos agricultores. Ainda que inicialmente estivessem previstas ações fundiárias, hídricas e instrumentos de política agrícola, a intervenção do PAPP concentrou-se em ações comunitárias com ênfase na redução da pobreza rural. Dizia respeito a um referencial de política pública para a agricultura familiar centrado em medidas de "alívio à pobreza", não reconhecendo a importância econômica desta categoria social no país. Com efeito, em 1995, o PAPP passou a denominar-se Programa de Combate à Pobreza Rural.

Já nos anos 1990, com a abertura democrática, maior visibilidade e participação política do fórum da agricultura familiar, com a mudança paradigmática no fórum científico e a partir das ideias e interesses do fórum da comunicação política, o PRONAF foi criado marcando o reconhecimento do Estado brasileiro à importância econômica e social da agricultura familiar. Resultado da negociação de ideias e de interesses e do próprio ambiente institucional onde se encontra inserido (Aquino e Schneider, 2010; Bastos, 2006), o PRONAF apresenta um referencial de política pública produtivista. Como evidenciaram alguns estudos, esse Programa tem sido apropriado principalmente por agricultores familiares mais capitalizados, geralmente localizados na Região Sul do Brasil, e, não raro, os recursos têm sido aplicados em produtos típicos das cadeias agroindustriais do país que são bastante competitivas no mercado internacional, as quais são controladas por poucas empresas do sistema agroindustrial 
e cuja forma de produção está assentada no uso generalizado de insumos modernos (Aquino e Schneider, 2010; Mattei, 2006; Kageyama, 2003; Neuman e Ferreira, 2002). Como mencionaram alguns entrevistados, ainda que com condições creditícias diferenciadas, o PRONAF pouco tem se diferenciado do modelo de crédito rural tradicional.

Por sua vez, o PAA foi construído em um contexto marcado pelo debate da fome e da segurança alimentar e nutricional. Conforme discutido acima, uma mudança nos porta-vozes do fórum da comunicação política em 2002 trouxe novas ideias ao fórum de comunidades de política pública, e com elas "novos" atores e também "novas" ideias dos fóruns da segurança alimentar e nutricional, fórum agroecológico e fórum científico. No bojo do Projeto Fome Zero e da recriação do CONSEA, o PAA aliou elementos da política agrícola e componentes da política de segurança alimentar, apresentando um referencial de política pública orientado pelo enfoque da segurança alimentar e nutricional.

Se esses constituem três referenciais distintos de política pública para a agricultura familiar, é importante notar que os mesmos convivem atualmente no fórum de comunidades de política pública. Estes referenciais foram e são (re)construídos por fóruns de produção de ideias com ideias e interesses distintos e/ou, também, podem ser mobilizados pelo mesmo grupo de atores dependendo do contexto e do ambiente institucional onde se encontram, dos recursos que dispõe, das suas estratégias de curto e de longo prazo, e da pressão política interna e externa ao fórum de produção de ideias. O fórum da agricultura familiar é um exemplo simbólico neste sentido, dada sua participação na construção do referencial de política pública do PRONAF e do PAA e na implantação do PAPP, como foi demonstrado neste trabalho. Nas pautas de reivindicações, em documentos e em manifestações públicas hodiernas de representantes desse fórum de produção de ideias é possível observar demandas relativas à continuidade e aperfeiçoamento do PRONAF, do PAA e do PCPR (sucessor do PAPP).

Desde a década de 1990, a agricultura familiar vem ganhando maior espaço no âmbito das políticas públicas e da academia brasileira e esta expressividade tende a se intensificar com a declaração da Assembléia Geral da Organização das Nações Unidas de que 2014 será o Ano Internacional da Agricultura Familiar. A agricultura familiar passa a ser cada vez mais reconhecida e valorizada no mundo como um ator-chave dos processos de desenvolvimento, seja pela sua importância na produção mundial de alimentos, seja em função do que isto representa em termos de promoção de formas mais equitativas de produção e, portanto, desenvolvimento inclusivo, social e econômico. Esta notoriedade exigirá reflexões de diferentes fóruns de produção de ideias sobre as ideias que vem sendo institucionalizadas em políticas públicas. No caso brasileiro, cabe indagar se estas ideias já institucionalizadas são suficientes e adequadas para responder a este papel atribuído à agricultura familiar no contexto atual. 


\title{
Notas
}

As entrevistas foram realizadas com gestores públicos, estudiosos do meio rural e da segurança alimentar, representantes de movimentos sociais, sindicais e ONG's relacionadas com a agricultura familiar, a segurança alimentar e a agroecologia. Estas entrevistas buscaram reconstruir a trajetória das políticas públicas estudadas e a participação destes atores sociais nestas.

2 Mas esta passagem de um fórum para outro não ocorre sem certa "deformação" ou "adaptação" das ideias, já que cada fórum é regulado por instituiç̧̃es e interesses específicos, o que obrigatoriamente demanda adaptações nos processos de importação/exportação inter-fóruns (Fouilleux, 2000).

3 O que não significa neutralidade política. Embora estes atores geralmente permaneçam em seus cargos e funções diante de mudanças no fórum da comunicação política, esta estabilidade não denota posicionamento neutro em relação aos porta-vozes deste fórum e ao seu referencial central.

4 Ainda não identificado com esta noção, mas que aglutinava os atores sociais que mais tarde (década de 1990) iriam aderir à identidade "agricultura familiar".

5 Sendo necessário para tanto, dentre outros elementos, garantir elevadas taxas de crescimento, apoiar o desenvolvimento industrial, conter a inflação, manter o equilíbrio na balança de pagamentos, promover a integração nacional, resolver os problemas das crescentes disparidades regionais, ocupar as regiões "vazias", prosseguir o processo de modernização do setor agrícola e dotá-lo de capacidade empresarial (Gonçalves Neto, 1997; Gonzalez, 1990).

6 O depoimento seguinte de um assessor do Banco Mundial no Brasil ilustra a ênfase dada por estes programas no "alívio" à pobreza rural: "O que significam esses programas para o desenvolvimento do Nordeste? É preciso ter em mente que eles em si não garantem o desenvolvimento. Se as comunidades não têm acesso à educação, aos meios de produção, a emprego, esses problemas continuam. Mas é inegável que há uma melhora nas condições de vida. Não é sem razão que o Banco Mundial chama esses programas de "alívio da pobreza". Eles são, sem dúvida, parte importante e necessária para uma estratégia de desenvolvimento, mas com certeza precisam ser complementados com outras ações." (Magalhães, 2010, grifos da autora).

Em 1990, os atores mencionados acima, marginais no interior do fórum da comunicação política nomeadamente aqueles vinculados ao Partido dos Trabalhadores (PT) e que haviam sido derrotados nas eleições presidenciais de 1989 - criaram um "governo paralelo" visando o acompanhamento crítico das ações do Governo Collor e à proposição de políticas públicas alternativas às ideias dominantes no interior do fórum da comunicação política. Ocorrida a consolidação do impeachment de Collor, esta instituição foi reorganizada no Instituto Cidadania, uma ONG com o propósito de discutir e propor políticas públicas, sendo Luis Inácio Lula da Silva o seu Presidente de honra.

\section{Referências}

ABRAMOVAY, R., (1992). Paradigmas do capitalismo agrário em questão. Campinas: Editora Hucitec/Editora da UNICAMP, 1992.

\begin{abstract}
ABRAMOVAY, R.; PIKETTY, M., (2005) Política de crédito do Programa Nacional de Fortalecimento da Agricultura Familiar (PRONAF): resultados e limites da experiência brasileira nos anos 90. Cadernos de Ciência \& Tecnologia, v.22, n.1, p.53-66, 2005.
\end{abstract}

AQUINO, J.; SCHNEIDER, S., (2010). 12 anos da política de crédito do PRONAF no Brasil (19962008): uma reflexão crítica. In: Congresso Latinoamericano de Sociologia Rural, 8, 2010, Porto de Galinhas. Anais... Porto de Galinhas: ALASRU, 2010.

BANCO MUNDIAL, (1994). Brazil: the management of agriculture, rural development and natural resources. Report n'. 11783-BR, v.l, 1994.

BASTOS, F., (2006). Ambiente institucional no financiamento da agricultura familiar. São Paulo: Editora Polis Ltda, 2006.

BELIK, W.; GRAZIANO DA SILVA, J.; TAKAGI, M., (2001). Políticas de combate à fome no Brasil. São Paulo em perspectiva, v.15, n.4, p.119-129, 2001.

BITTENCOURT, G.A., (2003). Abrindo a caixa-preta: o financiamento da agricultura familiar no Brasil. Dissertação (Mestrado em Desenvolvimento Econômico, Espaço e Meio Ambiente) Programa de Pós-Graduação em Desenvolvimento Econômico, Espaço e Meio Ambiente. IE/ UNICAMP, 2003. 
BRASIL, (1986). Lei no 7.486 de 6 de junho de 1986. Aprova as diretrizes do Primeiro Plano Nacional de Desenvolvimento (PND) da Nova República, para o período de 1986 a 1989, e dá outras providências. 1986.

(1974). Lei n. ${ }^{\circ} 6.151$ de 4 de dezembro de 1974. Dispõe sobre o Segundo Plano Nacional de Desenvolvimento (PND), para o período de 1975 a 1979. 1974.

CADONÁ, C.V., (2004). Movimento dos Pequenos Agricultores - MPA: o novo nasce das estradas. Dissertação (Mestrado em Educação) - Programa de Pós-Graduação em Educação nas Ciências, UNIJUÍ, ljuí, 2004.

CAMPOS, R.F.; CARDOSO, J.L., (2004). PRONAF: índices de financiamento e características da distribuição de crédito rural no Brasil de 1999 a 2001. Informações econômicas, v.34, n.11, 2004.

CARNEIRO, M.J., (1997). Política pública e agricultura familiar: uma leitura do PRONAF. Estudos sociedade e agricultura, v.8, p.70-82, 1997.

CASTRO, J., (1946). Geografia da fome. Rio de Janeiro: O Cruzeiro, 1946.

COELHO, C.N. 70 anos de política agrícola no Brasil (1931-2001). Revista de política agrícola, ano $\mathrm{X}, \mathrm{n} .03, \mathrm{p} .03-58,2001$.

CONFEDERAÇÃO NACIONAL DOS TRABALHADORES NA AGRICULTURA (CONTAG), (2001).

Congresso nacional dos trabalhadores e trabalhadoras rurais, 8, 2001, Brasília. Anais... Brasília: CONTAG, 2001.

(1979). Congresso nacional dos trabalhadores rurais, 3, 1979, Brasília. Anais... Brasília:

CONTAG, 1979.

(1973). Congresso nacional dos trabalhadores rurais, 2, 1973, Brasília. Anais... Brasília:

CONTAG, 1973.

DELGADO, G.C., (2005). Questão agrária no Brasil, 1950-2003. In: JACCOUD, L. Questão sociale políticas sociais no Brasil contemporâneo. Brasília: IPEA, 2005, p. 51-90.

DELGADO, N.G., (2010). O papel do rural no desenvolvimento nacional: da modernização conservadora dos anos 1970 ao Governo Lula. In: DELGADO, N.G. Brasil rural em debate: coletânea de artigos. Brasília: CONDRAF/NEAD, 2010, p.28-78.

(1989). Políticas diferenciadas de desenvolvimento rural no Brasil. Rio de Janeiro: IICA, 1989 (relatório de pesquisa).

ENCONTRO NACIONAL DE AGROECOLOGIA (ENA), (2002). Carta política. Rio de Janeiro, 2002.

FAVARETO, A., (2006). Agricultores, trabalhadores: os trinta anos do novo sindicalismo rural no Brasil. Revista brasileira de ciências sociais. v.21, n. 62, p. 27-45, 2006.

FOUILLEUX, È., (2011). Analisar a mudança: políticas públicas e debates num sistema em diferentes níveis de governança. Estudos Sociedade e Agricultura, v.19, n.1, p.88-125, 2011. (2003). La politique agricole commune et ses réformes: une politique à l'épreuve de la globalisation. Paris: L'Harmattan, 2003.

(2000). Entre production et institutionnalisation des idées: la réforme de la politique agricole commune. Revue française de science politique, v.50, n.2, p. 277-306, 2000.

GAZOLLA, M.; SCHNEIDER, S., (2005). As duas "caras" do PRONAF: produtivismo ou fortalecimento da produção para autoconsumo? In: Congresso Brasileiro de Economia, Administração e Sociologia Rural, 43, 2005, Ribeirão Preto. Anais... Ribeirão Preto: SOBER, 2005.

GONÇALVES NETO, W., (1997). Estado e agricultura no Brasil: política agrícola e modernização econômica brasileira, 1960-1980. São Paulo: Hucitec, 1997.

GONZALEZ, M.J.F. et al., (1990). O Brasil e o Banco Mundial: um diagnóstico das relações econômicas 1949-1989. Brasília: IPEA, 1990.

GOVERNO PARALELO., (1991). Política nacional de segurança alimentar. 1991.

GRAZIANO DA SILVA, J., (1999). Tecnologia e agricultura familiar. Porto Alegre: Editora da UFRGS, 1999. 
(1996). A nova dinâmica da agricultura brasileira. Campinas: Unicamp/IE, 1996.

GRISA, C. Políticas públicas para a agricultura familiar no Brasil: produção e institucionalização das ideias. Tese (Doutorado em Ciências Sociais) - Programa de Pós-Graduação de Ciências Sociais em Desenvolvimento Agricultura e Sociedade, CPDA/UFRRJ, Rio de Janeiro, 2012.

GRISA, C.; WESZ JUNIOR, V., (2010) Políticas públicas para a agricultura familiar: entre avanços e desafios. Boletim do OPPA, n.03, 2010.

GRITO DA TERRA BRASIL, (1994). Pauta nacional de reivindicações. Brasília: CUT/DNTR, CONTAG, MST, MAB, MONAPE, CNS, CAPOIB, 1994.

HALL, P.A, (1993). Policy paradigmes, social learning end the State. Comparative Politics, v.25, n.3, 1993.

INSTITUTO BRASILEIRO DE ANALISES SOCIAIS E ECONOMICAS (IBASE). Relatório PRONAF: resultados da etapa Paraná. Rio de Janeiro (RJ): IBASE, 2006.

INSTITUTO CIDADANIA, (2001). Projeto Fome Zero: uma proposta de política de segurança alimentar para o Brasil. 2001.

JOBERT, B., (2004). Une approche dialectique des politiques publiques: I'heritage de l'État en action. Pôle Sud, n.21, p. 43-54, 2004.

JOBERT, B.; MULLER, P., (1987). L'état en action. Paris: PUF, 1987.

KAGEYAMA, A., (2003). Produtividade e renda na agricultura familiar: efeitos do PRONAFcrédito. Agricultura. v.50, n.2, p.1-13, 2003.

KAGEYAMA, A. et al., (1990). O novo padrão agrícola brasileiro: do complexo rural aos complexos agroindustriais. In: DELGADO, G. Agricultura e políticas públicas. Brasília: IPEA, v.1, 1990, p. 113-223.

KAGEYAMA, A.; GRAZIANO DA SILVA, J., (1983). Os resultados da modernização agrícola dos anos 70. Estudos econômicos. v.13, n.3, p.537-559, 1983.

KUHN, T., (2003). A estrutura das revoluções científicas. 7ed. São Paulo: Perspectiva, 2003.

LAMARCHE, H., (1999). A agricultura familiar Il: do mito à realidade. Campinas: Editora da UNICAMP, 1999.

(1993). A agricultura familiar I: uma realidade multiforme. Campinas: Editora da

UNICAMP, 1993.

MAGALHÃES, A.R., (2010). Desenvolvimento comunitário e combate à pobreza no Nordeste. 2010. Disponível em: http://siteresources.worldbank.org/BRAZILINPOREXTN/ Resources/3817166-1185895645304/4044168-1186331278301/08 Depoimento.pdf Acesso: 07/06/2011.

MAGALHÃES, R.M., (2010). A política de apoio à agricultura familiar na conservação da biodiversidade no Brasil. Desenvolvimento e meio ambiente, n.21, p.89-101, 2010.

MALUF, R... (2001). Políticas agrícolas e de desenvolvimento rural e a segurança alimentar. In: LEITE, S. Políticas públicas e agricultura no Brasil. Porto Alegre: Editora da UFRGS, 2001, p.145-168.

MALUF, R.; MENEZES, F.; VALENTE, F., (1996). Contribuição ao tema da segurança alimentar no Brasil. Cadernos de Debate, v. iv, p. 66-88, 1996.

MATTEI, L., (2006). PRONAF 10 anos: mapa da produção acadêmica. Brasília: MDA, 2006.

MEDEIROS, L.S., (2010). Agricultura familiar no Brasil: aspectos da formação de uma categoria política. In: MANZANAL, M.; NEIMAN, G. Las agriculturas familiares del Mercosur: trayectorias, amenazas y desafios. Buenos Aires: CICCUS, 2010, p.131-152.

MENEZES, F., (2010). Participação social no Fome Zero: a experiência do CONSEA. In: GRAZIANO DA SILVA, J.; DEL GROSSI, M.E.; FRANÇA, C.G. Fome Zero: a experiência brasileira. Brasília: MDA, 2010, p.247-264. 
MUELLER, C.C. A política agrícola no Brasil: uma visão de longo prazo. Revista de política agrícola, ano xix (edição especial de aniversário do MAPA - 150 anos), p. 9-23, 2010.

MÜLLER, A.L.(2007). A construção das políticas públicas para a agricultura familiar no Brasil: o caso do Programa de Aquisição de Alimentos. Dissertação (Mestrado em Desenvolvimento Rural) Programa de Pós-Graduação em Desenvolvimento Rural (PGDR/UFRGS). Porto Alegre, 2007.

MULLER, P., (2008). Les politiques publiques. 7ed. Paris: PUF, 2008.

NEUMAN, P.S.; FERREIRA, P.E.R., (2002). Análise do PRONAF como política pública de promoção do desenvolvimento da agricultura familiar: o caso do município de Três Palmeiras-RS. In: Congresso da Associação Latino-Americana de Sociologia Rural, 6, 2002, Porto Alegre, Anais... Porto Alegre: ALASRU, 2002.

NORTH, D., (1991). Institution. Journal of economic perspectives, v.5, n.1, p. 97-112, 1991.

ORGANIZAÇÃO DAS NAÇÕES UNIDAS PARA AGRICULTURA E ALIMENTAÇÃO (FAO)/ INSTITUTO NACIONAL DE COLONIZAÇÃO E REFORMA AGRÁRIA (INCRA), (1996). Perfil da agricultura familiar no Brasil. Brasília: FAO/INCRA, 1996.

(1994). Diretrizes de política agrária e desenvolvimento sustentável para a pequena produção familiar. Brasília: FAO/INCRA, 1994.

PELIANO, A.M.M., (1993). O mapa da fome: subsídios à formulação de uma política de segurança alimentar. Brasília: IPEA (Documento de Política n.14), 1993.

PEREIRA, J.M.M., (2009). O Banco Mundial como ator político, intelectual e financeiro (1944-2008). Tese (Doutorado em História) - Programa de Pós-Graduação em História/UFF, 2009.

PESSANHA, L.D.R., (1998). Segurança alimentar como um princípio orientador de políticas públicas: implicações e conexões para o caso brasileiro. Tese (Doutorado em Desenvolvimento Agricultura e Sociedade) - Programa de Pós-Graduação de Ciências Sociais em Desenvolvimento Agricultura e Sociedade CPDA/UFRRJ, 1998.

PICOLOTTO, E.L., (2011). As mãos que alimentam a nação: agricultura familiar, sindicalismo e política. Tese (Doutorado em Desenvolvimento, Agricultura e Sociedade) - Programa de PósGraduação de Ciência Sociais em Desenvolvimento, Agricultura e Sociedade CPDA/UFRRJ, 2011.

PIERSON, P., (2003). Public policies as institutions. In: Yale Conference on Crafting and Operating Institutions, 2003, New Haven, Anais... New Haven: Yale University, 2003.

RADAELLI, C.M., (2000). Logiques de pouvoirs et récits dans les politiques publiques de l'Union Européene. Revue française de Science Politique, v. 50, n.2, p.255-275, 2000.

SABATIER, P.A.; JENKINS-SMITH, H.C., (1999). The advocacy coalition framework : an assessment. In: SABATIER, P.A. Theories of the policy process. Westview Press, 1999, p. 117-166. (2009). Policy Change and Learning: an advocacy coalition approach. Westview Press, 1993.

SABOURIN, E., (2009). Camponeses do Brasil: entre a troca mercantil e a reciprocidade. Rio de Janeiro: Garamont, 2009.

SANTOS, F.P., (2011). Coalizões de interesses e a configuração política da agricultura familiar no Brasil. Tese (Doutorado em Administração) - Escola de Administração de Empresas de São Paulo. FGV-SP. 2011.

SCHMIDT, V.A.; RADAELLI, C.M., (2004). Policy change and discourse in Europe: conceptual and methodological issues. West European Politics, v.27, n.2, p.183-210, 2004.

SCHNEIDER, S., CAZELLA, A.; MATTEI, L., (2004). Histórico, caracterização e dinâmica recente do Pronaf-Programa Nacional de Fortalecimento da Agricultura Familiar. In: SCHNEIDER, S.; SILVA, M.K.; MARQUES, P.E.M., (2004). Políticas públicas e participação social no Brasil rural. Porto Alegre: Editora da UFRGS, 2004. p.21-49. 
SHIKI, S., (2010). Política agrária e conservação da biodiversidade no Brasil. Estudos Sociedade e Agricultura, Rio de Janeiro, v.18, n.2, p.288-316, 2010.

SILVA, L.M.S.; MARTINS, S.R., (2010). Impactos das limitações epistêmicas sobre sustentabilidade nas ações do PRONAF na porção sudeste do Pará. Agricultura Familiar, v.8, p.728, 2010.

SOARES, R.P., (1996). O financiamento do Banco Mundial ao Programa de Apoio ao Pequeno Produtor Rural do Nordeste (PAPP). Brasília: IPEA, 1996. (Texto para discussão n. 435)

SOUZA FILHO, H.M.; BUAINAIN, A.M.; SILVEIRA, J.M., (2006). Os impactos socioeconômicos imediatos do Programa de Combate à Pobreza. In: MIRANDA, C.; COSTA, C. Reflexões e recomendações sobre estratégias de combate à pobreza. Brasília: IICA (Série Desenvolvimento Rural Sustentável, v.4), 2006, p. 07-54.

SPERANZA, J.S., (2005). Desenvolvimento local: aproximações entre o Banco Mundial e o debate brasileiro: limites ou possibilidades? Dissertação (Mestrado em Desenvolvimento, Agricultura e Sociedade) - Programa de Pós-Graduação de Ciências Sociais em Desenvolvimento, Agricultura e Sociedade - CPDA/UFRRJ, 2005.

SUREL, Y., (2000). L'intégration européenne vue par l'approche cognitive et normative des politiques publiques. Revue française de science politique. v.50, n.2, p. 235-254, 2000.

(1995). Les politiques publiques comme paradigmes. In: FAURE, A.; POLLET, G.; WARIN, P. La construction du sens dans les politiques publiques: débats autour de la notion de référentiel. Paris: Éditions L'Harmattan, 1995, p.125-151.

TOLEDO, E.N.B., (2009). O PRONAF em Salvador das Missões: contradições de uma política de crédito. Dissertação (Mestrado em Desenvolvimento Rural) - Programa de Pós-Graduação em Desenvolvimento Rural (PGDR/UFRGS).Porto Alegre, 2009.

VEIGA, J.E., (1991). O desenvolvimento agrícola: uma visão histórica. São Paulo: Editora da Universidade de São Paulo/Hucitec, 1991.

WEID, J.M., (2006). A transição agroecológica das políticas de crédito voltadas para a agricultura familiar. Revista agriculturas, v.3, n.1, p.18-20, 2006.

WILKINSON, J., (1986). O Estado, a agroindústria e a pequena produção. São Paulo/Salvador: Hucitec/CEPA-BA, 1986.

ZYL, J. et al., (1995). Decentralized rural development and enhanced communilty participation: a case study from Northeast Brazil. Policy research working paper 1498. Washington: The World Bank, 1995.

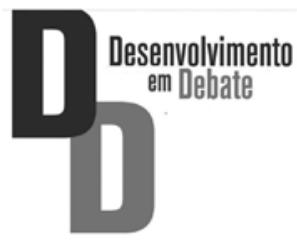

